\title{
Research
}

\section{Early detection of multiple myeloma in primary care using blood tests:}

\author{
a case-control study in primary care
}

\begin{abstract}
\section{Background}

Multiple myeloma is a haematological cancer characterised by numerous non-specific symptoms leading to diagnostic delay in a large proportion of patients.
\end{abstract}

\section{Aim}

To identify which blood tests are useful in suggesting or excluding a diagnosis of myeloma.

\section{Design and setting}

A matched case-control study set in UK primary care using routinely collected data from the Clinical Practice Research Datalink.

\section{Method}

Symptom prevalence and blood tests were analysed up to 5 years before diagnosis in 2703 cases and 12157 matched controls. Likelihood ratios (LR) were used to classify tests or their combinations as useful rule-in tests ( $L R+=\geq 5)$, or rule-out tests ( $L R-=\leq 0.2$ )

\section{Results}

Raised plasma viscosity (PV) had an LR+ = 2.0, $95 \%$ confidence interval $[\mathrm{Cl}]=1.7$ to 2.3 ; erythrocyte sedimentation rate (ESR) 1.9, $95 \% \mathrm{Cl}=1.7$ to 2.0 ; and $\mathrm{C}$-reactive protein (CRP) $1.2,95 \% \mathrm{Cl}=1.1$ to 1.4 . A normal haemoglobin had an $\mathrm{LR}-=0.42,95 \% \mathrm{Cl}=0.39$ to 0.45 ; calcium LR- $=0.81,95 \% \mathrm{Cl}=0.78$ to 0.83 ; and creatinine LR- $=0.80,95 \% \mathrm{Cl}=0.77$ to 0.83 . The test combination with the lowest LRwas all normal haemoglobin with calcium and $\mathrm{PV}$, which had an LR- $=0.06,95 \% \mathrm{Cl}=0.02$ to 0.18 , though the LR- for normal haemoglobin and $\mathrm{PV}$ together was $0.12195 \% \mathrm{Cl}=0.07$ to 0.23)

\section{Conclusion}

Plasma viscosity and ESR are better for both ruling in and ruling out the disease compared with C-reactive protein. A combination of a normal ESR or PV and normal haemoglobin is a simple rule-out approach for patients currently being tested in primary care.

\section{Keywords}

blood, diagnosis; case-control studies inflammatory; multiple myeloma; primary care.

\section{INTRODUCTION}

Multiple myeloma is a rare malignancy, characterised by clonal proliferation of plasma cells. These cells secrete immunoglobulins (paraproteins), which can lead to plasma hyperviscosity and renal damage. Proliferation of plasma cells can lead to bone marrow suppression, and may cause hypercalcaemia. These various features of myeloma give rise to different symptoms, such as bone pain from direct skeletal involvement, fatigue from anaemia, or headache from hyperviscosity. Presentation with complications from hypercalcaemia or renal failure is also common.

Diagnosis of myeloma is often difficult. Patients with myeloma have the longest intervals from initial symptom reporting to diagnosis of all common cancers, with the most consultations in primary care before referral., ${ }^{1,2}$ Longer diagnostic intervals in myeloma are associated with more advanced disease stages and more complications at diagnosis. ${ }^{3,4}$ Patients who are not referred to the appropriate department generally experience a longer diagnostic process. ${ }^{5} \mathrm{~A}$ large proportion of patients are diagnosed through emergency presentations, with concomitant worse survival. ${ }^{6,7}$ A recent study reported that $77 \%$ of all myeloma emergency presentations had at least one primary care consultation before the emergency and 56\% of these had at least three. ${ }^{8}$

C Koshiaris, MSc, statistician; A Van den Bruel MD, PhD, associate professor of general practice JL Oke, DPhil, senior statistician; BD Nicholson MSc, MRCGP, clinical researcher, Nuffield Department of Primary Care Health Sciences, University of Oxford, Oxford. E Shephard, PhD, CPsychol, research fellow; W Hamilton, MD, FRCP, FRCGP, professor of primary care diagnostics, University of Exeter Medical School, Exeter. M Braddick, MRCP, GP, Chiddenbrook Surgery, Crediton, Devon.

Address for correspondence

Constantinos Koshiaris, Nuffield Department
This prolonged diagnostic process probably represents the non-specific nature of myeloma symptoms, with positive predictive values for symptoms $<1 \%$, even in combination. ${ }^{9}$ Guidance from the National Institute for Health and Care Excellence (NICE) uses an urgent cancer threshold for referral of $3 \% .^{10}$ In myeloma, symptoms need to be combined with abnormal blood results such as full blood counts (FBC), calcium, and inflammatory markers to reach that threshold. The inflammatory markers C-reactive protein (CRP), erythrocyte sedimentation rate (ESR), and plasma viscosity (PV), when considered together, have been used for diagnosing myeloma but have not been reported individually. ${ }^{11-13}$

The aims of this study are to identify the best inflammatory marker for initial investigation of possible myeloma, useful blood tests for ruling out symptomatic myeloma, and how to distinguish early and late features of the disease. Symptoms can occur up to 2 years before diagnosis in other cancers, but little is known about the timing of symptoms and abnormal blood test results before diagnosis in myeloma. ${ }^{14,15}$ The latter can explain why some features have better rule-out properties than others as features that manifest very late in the diagnosis can be useful for ruling in the disease but not as useful for ruling it out.

of Primary Care Health Sciences, University of Oxford, Radcliffe Primary Care Building, Radcliffe Observatory Quarter, Woodstock Road, Oxford OX2 6GG, UK

Email: constantinos.koshiarisaphc.ox.ac.uk Submitted: 20 November 2017; Editor's response: 1 February 2018; final acceptance: 14 March 2018. (B) British Journal of General Practice

This is the full-length article (published online 14 Aug 2018) of an abridged version published in print. Cite this version as: Br J Gen Pract 2018; DOI: https://doi.org/10.3399/bjgp18X698357 


\section{How this fits in}

Patients with myeloma experience some of the longest diagnostic intervals, which could be due to the non-specific nature of their symptoms. The results of this study suggest that the best inflammatory markers to supplement symptoms of myeloma are plasma viscosity and erythrocyte sedimentation rate, while C-reactive protein is unhelpful. In addition the combination of a normal haemoglobin and plasma viscosity can be used to rule out the disease on patients currently being tested in primary care. These results further demonstrate that the full blood count components and especially low haemoglobin are among the earliest presentations of the disease, which may allow the diagnosis to be expedited.

\section{METHOD}

\section{Study design}

This is an extension of a 2015 study that quantified the risk of multiple myeloma from symptoms reported in primary care using records from the Clinical Practice Research Datalink (CRPD). ${ }^{9}$ Briefly, the study had a case-control design with 2703 cases and 12157 matched controls based on age, sex, and general practice. Cases were selected if patients were $>40$ years of age with a myeloma diagnosis between January 2000 and December 2009. Date of diagnosis was defined as the first myeloma Read code, which was also used as the index date for the controls. Exclusion criteria included cases or controls with $<1$ year of records, cases without controls, controls with myeloma, and controls that did not seek medical care after registration. The study identified eleven symptoms (back pain, chest pain, chest infections, shortness of breath, nausea, fracture, joint pain, bone pain, weight loss, rib pain, and nosebleed] and five abnormal blood investigations associated with myeloma lcytopenia, raised inflammatory markers, raised creatinine, raised mean corpuscular volume, and hypercalcaemia).

\section{Variable definitions}

Symptoms and investigations were identified using libraries of Read codes. Abnormal blood test results were defined as results above or below the local laboratory's normal range. Implausible test values were excluded. Combinations of blood tests, such as FBC and calcium, were defined as positive if at least one of the test results was abnormal. For the combination to be defined as negative, all tests in the combination were required to be normal. For the FBC, which has multiple constituent parts, for example, white cell count (WCC), haemoglobin, and platelets, a result was defined abnormal if at least one of the parts indicated cytopenia (low haemoglobin, WCC, or platelets).

\section{Analysis}

Symptom prevalence and blood tests were analysed up to 5 years before diagnosis. Each inflammatory marker was examined separately using conditional logistic regression in order to examine its association with myeloma compared with matched controls, its predictive performance was quantified using positive likelihood ratios (LR+). To identify the best combinations for ruling out myeloma, the negative likelihood ratio (LR-) was estimated for each test individually and in combination. Positive likelihood tests indicate how many times more likely a positive test occurs in individuals with the disease compared with individuals without the disease, and negative likelihood tests represent how much less likely a negative result will occur in individuals with the disease compared with a healthy individual. A useful rule-in test was defined as one with an LR+ $>5$ and a useful rule-out test one with an LR- $<0.2 .16,17$

Each combination included a different inflammatory marker. The constituent parts of the FBC were examined either separately or altogether. The analysis was restricted to patients who had been tested or had a combination of tests.

To examine when symptoms and investigations start to indicate symptomatic myeloma and to distinguish between the early and late features, the 5-year period before diagnosis was broken down into 90-day intervals, and symptom occurrence and blood test results in these periods were identified. The results for each 90-day interval were summarised using proportions for binary variables (symptoms) and means for continuous variables (blood test results).

\section{RESULTS}

Baseline characteristics of the population under investigation can be found in the original report, ${ }^{9}$ but, briefly, total number of patients was the same as the 2015 study, $N=14860$, and the median age was 73 years with $53 \%$ being male.

Within the year before diagnosis 55\% (8221/14 860) participants had at least one blood test leither FBC, calcium, creatinine, or one of the inflammatory markers) with testing being more prevalent in cases $178 \%$, 
2097/2703) compared to controls (50\%, $6124 / 12$ 157). The most common tests were creatinine (50\%, 7407/14860) and FBC (40\%, 5934/14860); the least common test was calcium (19\%, 2809/14 860). Among the inflammatory markers the most common tests included ESR, followed by CRP and $\mathrm{PV}$. The most common test combination was FBC with creatinine and ESR $113 \%$, (1864/14 860).

At 3 years before diagnosis, $84 \%$ (2270/2703) of patients with myeloma had at least one blood test compared with $66 \%(8058 / 12157)$ in the controls, and at 5 years before diagnosis 85\% (2307/2703) of the cases had a test compared with $70 \%$ (8524/12 157) of the controls.

\section{Rule-in tests}

Associations between raised inflammatory markers and a myeloma diagnosis are shown on Table 1. During the year before diagnosis 85\% (844) of patients with myeloma had an abnormal ESR compared with $46 \%$ (546) of controls lodds ratio [OR] 5.7; $95 \% \mathrm{Cl}=4.1$ to $8.0 ; P<0.001 ; \mathrm{LR}+1.9,95 \%$ $\mathrm{Cl}=1.7$ to 2.0 ), $81 \%$ (162) had an abnormal PV compared with $41 \%$ (95) of controls IOR 4.4; $95 \% \mathrm{Cl}=2.2$ to $8.8 ; P<0.001 ; L R+2.0$, $95 \% \mathrm{Cl}=1.7$ to 2.3 ), and $46 \%$ (294) had an abnormal CRP compared with 37\% (238) of controls (OR 1.5; $95 \% \mathrm{Cl}=1.0$ to 2.2 ; $P=0.05 ; L R+1.2,95 \% \mathrm{Cl}=1.1$ to 1.4$)$. The rule-in properties for the rest of the tests that are published in the original report included cytopenia (OR 5.4, 95\% Cl=4.6 to 6.4), raised creatinine (OR $1.8,95 \% \mathrm{Cl}=1.5$ to 2.2 ), raised mean corpuscular volume (MCV) (OR 3.1, $95 \% \mathrm{Cl}=2.1$ to 4.1 ), and hypercalcaemia (OR $11.4,95 \% \mathrm{Cl}=7.1$ to 18 ).

\section{Rule-out tests}

No single blood test was able to rule out myeloma (Table 2), though confidence intervals for each marker approached the pre-specified cut-off of LR 0.2. A normal haemoglobin performed much better as a rule-out test (LR- $0.42,95 \% \mathrm{Cl}=0.39$ to 0.45) compared with calcium (LR-0.81, $95 \% \mathrm{Cl}=0.78$ to 0.83 ) and creatinine (LR- $0.80,95 \% \mathrm{Cl}=0.77$ to 0.83 ). For inflammatory markers, the best ones for ruling out the disease were ESR (LR- 0.28 , $95 \% \mathrm{Cl}=0.24$ to 0.33 ) and PV (LR- 0.32, $95 \% \mathrm{Cl}=0.24$ to 0.44 ). Ruling out is achieved by most of the test combinations, with the lowest LR- being when haemoglobin, calcium, and PV are all normal (LR- 0.06 , $95 \% \mathrm{Cl}=0.02$ to 0.19 ). For two test combinations the lowest LR- was achieved by normal haemoglobin and normal PV (LR- $0.12,95 \% \mathrm{Cl}=0.07$ to 0.23 ). Details of negative likelihood ratios for when whole FBC is used are available from authors upon request, but results were very similar to using just haemoglobin. A table illustrating how the post-test probability is affected depending on the background prevalence and the estimate of the likelihood ratio is also available from the authors.

\section{Timing of symptoms and investigations}

Figures 1 and 2 illustrate the mean values for blood tests for each 3-month period in the 5 years leading up to the date of myeloma diagnosis. In patients with myeloma, but not in control patients, haemoglobin values started to decrease approximately 3 years before diagnosis in both males and females, and the mean haemoglobin value met the WHO criteria for anaemia throughout the final 24 months in males $(13 \mathrm{~g} / \mathrm{dL})$ and final 15 months for females $(12 \mathrm{~g} / \mathrm{dL}) .^{18}$ Mean corpuscular volume started to rise approximately 1.5 years before diagnosis, though the increase was minor. WCC and platelets remained stable and within the normal range at all time points. The mean calcium and creatinine values rose rapidly in the last 3-6 months before diagnosis. ESR and PV values started to increase at approximately 2 years before diagnosis. Importantly, CRP showed no difference between cases and controls at any point.

\section{Table 1. Comparison of inflammatory markers in the year before diagnosis}

\begin{tabular}{|c|c|c|c|c|c|c|c|c|}
\hline \multirow[b]{3}{*}{$\begin{array}{l}\text { Blood } \\
\text { test }\end{array}$} & \multicolumn{5}{|c|}{ Blood test results } & \multirow[b]{3}{*}{$\begin{array}{l}\text { Odds ratio } \\
\text { (95\% Cl) }\end{array}$} & \multirow[b]{3}{*}{$P$-value } & \multirow[b]{3}{*}{$\begin{array}{c}\text { LR+ } \\
(95 \% \mathrm{Cl})\end{array}$} \\
\hline & \multirow[b]{2}{*}{$\begin{array}{l}\text { Number } \\
\text { tested, }{ }^{\text {a }} n\end{array}$} & \multicolumn{2}{|c|}{ Cases } & \multicolumn{2}{|c|}{ Controls } & & & \\
\hline & & $\begin{array}{c}\text { Abnormal } \\
(\%)\end{array}$ & $\begin{array}{c}\text { Normal } \\
\text { (\%) }\end{array}$ & $\begin{array}{c}\text { Abnormal } \\
\text { (\%) }\end{array}$ & $\begin{array}{c}\text { Normal } \\
{[\%]}\end{array}$ & & & \\
\hline ESR & 2192 & 844 (85) & $154(15)$ & 546 (46) & $648(54)$ & 5.7 (4.1 to 8.0$)$ & $<0.001$ & 1.9 (1.7 to 2.0$)$ \\
\hline CRP & 1274 & $294(46)$ & $341(54)$ & 238 (37) & 401 (63) & 1.5 (1.0 to 2.2 ) & 0.05 & $1.2(1.1$ to 1.4$)$ \\
\hline PV & 433 & $162(81)$ & 39 (19) & $95(41)$ & 137 (59) & 4.4 (2.2 to 8.8 ) & $<0.001$ & 2.0 (1.7 to 2.3) \\
\hline
\end{tabular}

Sample size corresponds to the number of patients who had the test or a particular combination of tests. $C R P=C$-reactive protein. $E S R=$ erythrocyte sedimentation rate. $L R+=$ positive likelihood ratio. $P V=$ plasma viscosity. 


\section{Table 2. The rule-out value of individual and combinations of blood investigations for myeloma}

\begin{tabular}{|c|c|c|c|c|c|c|c|c|}
\hline \multirow[b]{2}{*}{ Investigations } & \multicolumn{5}{|c|}{ Blood test results } & \multirow[b]{2}{*}{$\begin{array}{l}\text { Sensitivity, } \\
\%(95 \% \mathrm{CI})\end{array}$} & \multirow[b]{2}{*}{$\begin{array}{l}\text { Specificity, } \\
\%(95 \% \mathrm{Cl})\end{array}$} & \multirow[b]{2}{*}{ LR- $(95 \% \mathrm{CI})$} \\
\hline & $\begin{array}{l}\text { Number } \\
\text { tested, }{ }^{\text {a } n}\end{array}$ & $\begin{array}{c}\text { True } \\
\text { positive }\end{array}$ & $\begin{array}{c}\text { False } \\
\text { positive }\end{array}$ & $\begin{array}{c}\text { False } \\
\text { negative }\end{array}$ & $\begin{array}{c}\text { True } \\
\text { negative }\end{array}$ & & & \\
\hline \multicolumn{9}{|l|}{ Individual tests } \\
\hline ESR & 2192 & 844 & 546 & 154 & 648 & 85 (82 to 87) & 54 (51 to 57 ) & 0.28 (0.24 to 0.33) \\
\hline PV & 433 & 162 & 95 & 39 & 137 & 81 (74 to 86 ) & 59 (52 to 64$)$ & 0.32 (0.24 to 0.44$)$ \\
\hline $\mathrm{Hb}$ & 5934 & 1243 & 912 & 596 & 3183 & 68 (65 to 70$)$ & 78 (76 to 79$)$ & 0.42 (0.39 to 0.45$)$ \\
\hline CAL & 2809 & 246 & 43 & 893 & 1627 & 22 (19 to 24$)$ & 98 (97 to 0.98) & $0.81(0.78 \text { to } 0.83)^{b}$ \\
\hline CREAT & 7407 & 648 & 1021 & 1202 & 4536 & 35 (33 to 37) & 82 (81 to 83) & $0.80(0.77 \text { to } 0.83)^{b}$ \\
\hline CRP & 1274 & 316 & 281 & 319 & 358 & 46 (42 to 50$)$ & 63 (59 to 67) & $0.87(0.78 \text { to } 0.94)^{b}$ \\
\hline \multicolumn{9}{|l|}{ Combinations (two tests) } \\
\hline $\mathrm{Hb}$ and $\mathrm{PV}$ & 396 & 175 & 119 & 10 & 92 & 95 (90 to 97) & 44 (37 to 50) & $0.12(0.07 \text { to } 0.23)^{c}$ \\
\hline $\mathrm{Hb}$ and ESR & 2071 & 884 & 603 & 72 & 512 & 93 (91 to 94) & 46 (43 to 49$)$ & $0.16(0.13 \text { to } 0.21)^{c}$ \\
\hline $\mathrm{Hb}$ and $\mathrm{CRP}$ & 1193 & 491 & 311 & 111 & 280 & 84 (80 to 86 ) & 47 (43 to 52) & 0.39 (0.32 to 0.47$)$ \\
\hline \multicolumn{9}{|l|}{ Combinations (three tests) } \\
\hline $\mathrm{Hb}, \mathrm{CREAT}$, and PV & 356 & 165 & 111 & 6 & 74 & 97 (93 to 99) & 40 (33 to 47) & $0.09(0.04 \text { to } 0.20)^{c}$ \\
\hline $\mathrm{Hb}, \mathrm{CAL}$, and $\mathrm{PV}$ & 213 & 128 & 49 & 3 & 33 & 98 (94 to 100) & 40 (30 to 52$)$ & $0.06(0.02 \text { to } 0.18)^{c}$ \\
\hline $\mathrm{Hb}, \mathrm{CREAT}$, and ESR & 1864 & 823 & 599 & 54 & 388 & 94 (92 to 95) & 39 (36 to 42) & $0.16(0.12 \text { to } 0.21)^{c}$ \\
\hline $\mathrm{Hb}, \mathrm{CAL}$, and ESR & 1146 & 590 & 286 & 45 & 225 & 93 (91 to 95) & 44 (40 to 49) & $0.16(0.12 \text { to } 0.22)^{c}$ \\
\hline $\mathrm{Hb}, \mathrm{CREAT}$, and CRP & 1115 & 505 & 341 & 70 & 199 & 88 (85 to 90) & 37 (33 to 41) & 0.33 (0.26 to 0.42 ) \\
\hline $\mathrm{Hb}, \mathrm{CAL}$, and CRP & 722 & 363 & 160 & 64 & 135 & 85 (81 to 88 ) & 46 (40 to 52) & 0.33 (0.25 to 0.42 ) \\
\hline \multicolumn{9}{|l|}{ Combinations (four tests) } \\
\hline $\mathrm{Hb}, \mathrm{CAL}, \mathrm{CREAT}$, and PV & 211 & 127 & 50 & 3 & 31 & 98 (93 to 100) & 38 (28 to 50$)$ & $0.06(0.02 \text { to } 0.19)^{c}$ \\
\hline $\mathrm{Hb}, \mathrm{CAL}, \mathrm{CREAT}$, and ESR & 1103 & 569 & 309 & 39 & 186 & 94 (91 to 95) & 38 (33 to 42) & $0.17(0.12 \text { to } 0.24)^{c}$ \\
\hline $\mathrm{Hb}, \mathrm{CAL}, \mathrm{CREAT}$, and CRP & 706 & 373 & 189 & 44 & 100 & 89 (86 to 92) & 35 (29 to 40) & 0.31 (0.22 to 0.42) \\
\hline
\end{tabular}

${ }^{a}$ Sample size corresponds to the number of patients who had the test or a particular combination of tests. ${ }^{b} N R L=$ negative likelihood ratio ( $\left.L R-\right)>0.8$. ${ }^{c} N R L \leq 0.2$. CAL $=$ calcium. $C R E A T=$ creatinine. $C R P=C$-reactive protein. $E S R=$ erythrocyte sedimentation rate. $H b=$ haemoglobin. $L R-=$ negative likelihood ratio. $P V=$ plasma viscosity.

Some symptoms, back pain, rib pain, chest infections, chest pain, and nosebleed, become more common in patients with myeloma compared with controls at approximately 2 years before diagnosis (result figures for symptoms are available from the authors). Symptoms suggesting advanced disease, such as fractures, weight loss, and nausea, are more common up to 1 year before diagnosis, especially within the last 3 months.

\section{DISCUSSION}

\section{Summary}

Myeloma is a difficult disease to identify, especially in its early stages. The combined use of FBC, ESR, or PV and calcium in certain cases on patients currently being tested in primary care appears to be sufficient to select those who may have the disease. Those with test abnormalities can proceed to more specific primary care blood testing, and if these tests are abnormal they warrant haematology expertise. In contrast, if the initial tests are normal, myeloma, which was unlikely in the first place, as it is so rare, becomes extremely unlikely, and another cause should be sought for the patient's symptoms.
This study demonstrates that ESR and PV have better diagnostic performance for myeloma, both as rule-in tests when abnormal, and rule-out tests when normal in contrast to CRP, which has very little value in myeloma diagnosis. Both calcium and creatinine rise before a diagnosis of myeloma, but a negative calcium or creatinine result alone should not be used to rule it out because they only start to rise late in the disease process. Conversely, haemoglobin starts to decline much earlier, subsequently making the FBC a more useful rule-out test. In the year before diagnosis, $95 \%$ of patients with myeloma having $\mathrm{PV}$ and $\mathrm{FBC}$ tests have at least one abnormality $(95 \% \mathrm{Cl}=90$ to $97 \%)$. In practical terms, the combination of normal ESR or PV and normal haemoglobin can be used to rule out myeloma in patients presenting with symptoms potentially associated with myeloma, such as back pain. Non-specific symptoms occur up to 2 years before diagnosis, with more specific symptoms occurring in the last year before diagnosis.

\section{Strengths and limitations}

Strengths include the large sample size 

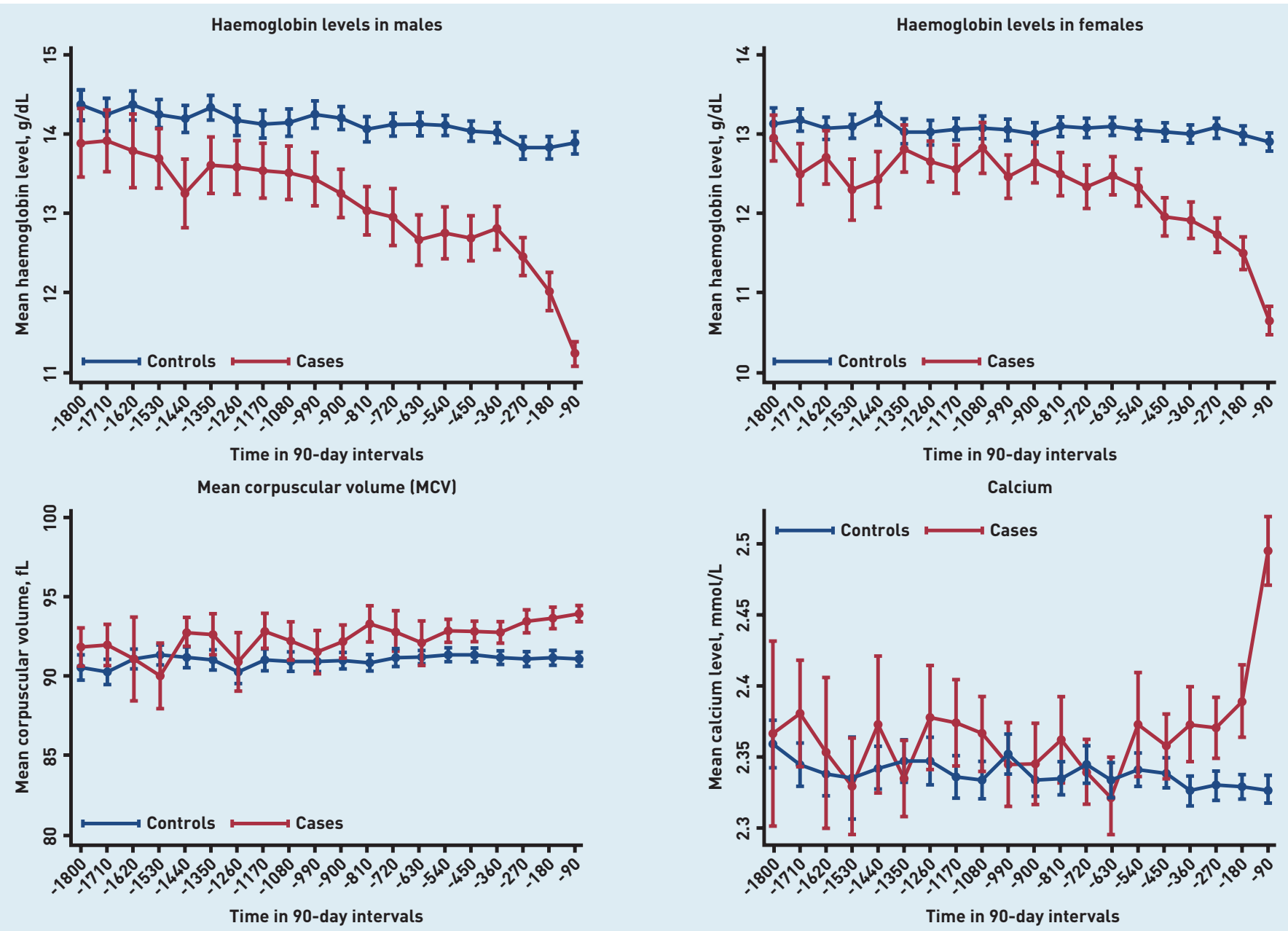

Time in 90-day intervals

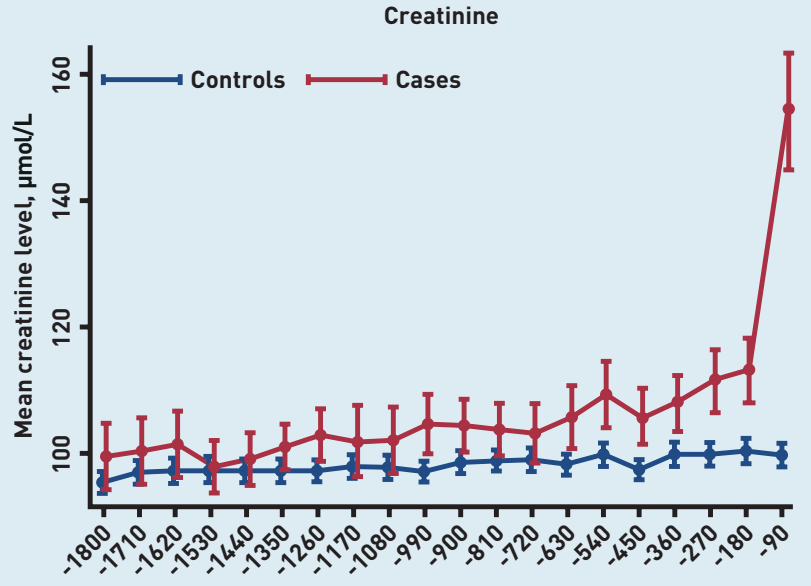

Time in 90-day intervals

Figure 1. Haemoglobin, mean corpuscular volume, calcium, and creatinine trajectories up to 5 years before diagnosis. Time before diagnosis is split into 90-day intervals and the mean test value for each group is displayed with a $95 \%$ confidence interval. representative of the UK and the primary care setting, both of which increase the generalisability of the results. Limitations include potential overestimation of diagnostic accuracy measures with the case-control design. ${ }^{19}$ Another limitation is missing data, as not all patients have been tested. If patients who have been tested differ systematically from those who were not tested with respect to the test lone potential reason might be that sicker patients are more likely to be tested), this may lead to under- or overestimation of the sensitivity, specificity, and likelihood ratios reported here. The authors, therefore, suggest exercising caution in extrapolating their findings to patients not currently being tested in primary care. As with most clinical 


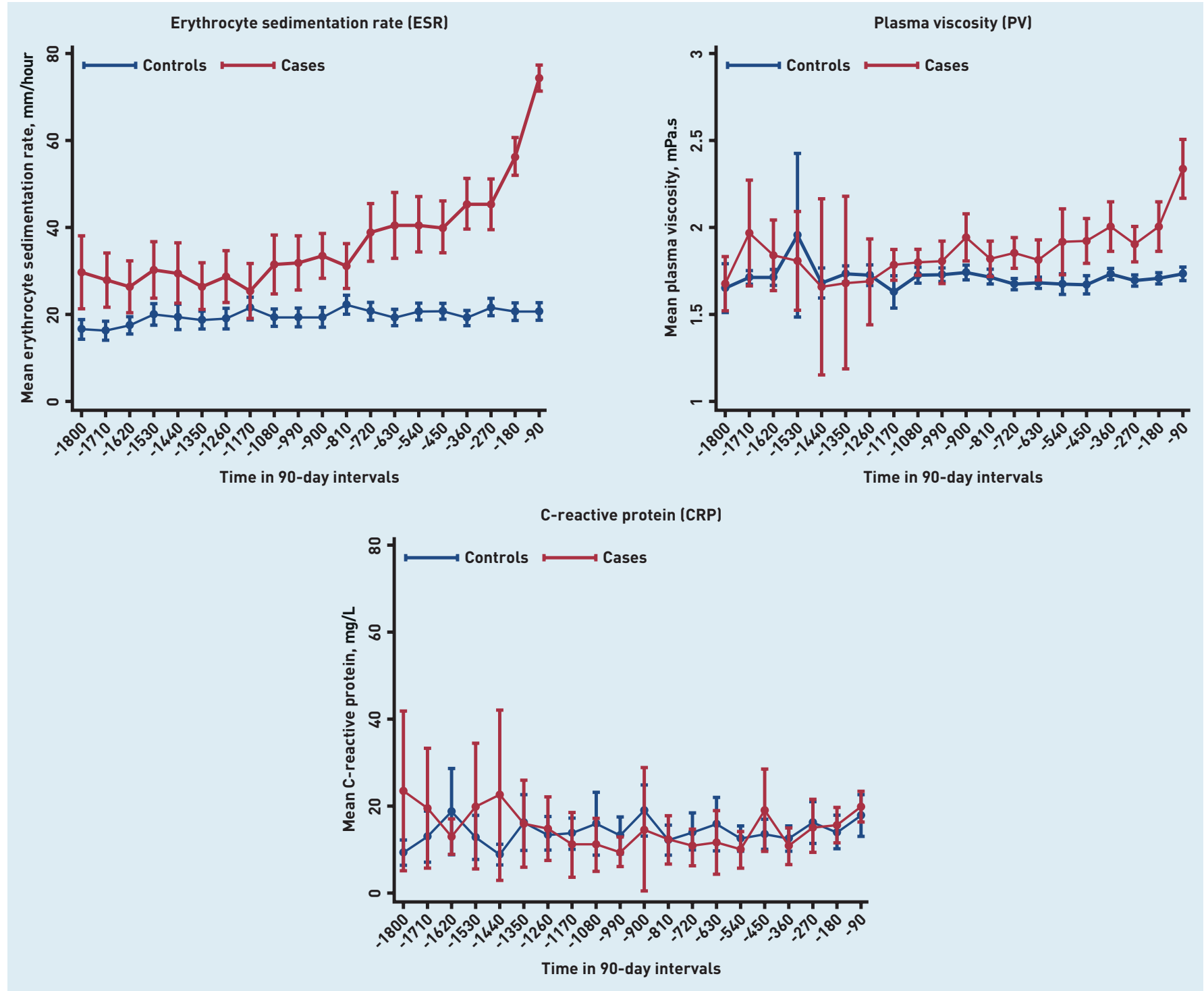

Figure 2. Inflammatory marker trajectories up to 5 years before diagnosis. Time before diagnosis is split into 90-day intervals and the mean test value is displayed for cases and controls with a $95 \%$ confidence interval. databases, there will be some underreporting or under-recording of symptoms, which can influence association measures. ${ }^{20}$

\section{Comparison with existing literature}

A Scandinavian study of 167 blood donors who developed myeloma has previously identified declining haemoglobin for 3 years before diagnosis, similar to the results presented here. ${ }^{21}$ No similar reports could be found for the timing of hypercalcaemia or reduced kidney function, though hypercalcaemia is common in patients with advanced cancer stages. ${ }^{22}$ Similarly, no reports in which myeloma symptoms were investigated over time could be found

NICE guidelines currently recommend the use of PV or ESR when myeloma is suspected. ${ }^{23}$ Results from this current study strongly support this recommendation. ESR has been reported as a good prognostic marker for myeloma with higher values of ESR associated with a more advanced cancer stage. ${ }^{24}$ In contrast, CRP is not useful as an initial investigation if myeloma is suspected: previous reports have concentrated on its use in prognosis rather than diagnosis. ${ }^{25,26}$

\section{Implications for practice}

Myeloma diagnosis could potentially be expedited by the use of simple blood tests in patients with back pain, rib pain, chest pain, and recurrent chest infections, which have been identified as early presentations of myeloma. With a sensitivity value $\geq 93 \%$ of normal haemoglobin and an inflammatory marker (PV or ESR), the possibility of myeloma is extremely low. Adding CRP or creatinine adds little additional sensitivity. Conversely, in a patient reporting relevant symptoms, with abnormalities in one of these two tests, it is reasonable for the clinician 
to request protein electrophoresis and urinary Bence Jones protein tests urgently. This should expedite myeloma diagnosis, without increasing haematology referrals. Hypercalcaemia is a high-risk marker of possible myeloma. Normal calcium levels do not make myeloma sufficiently less likely for calcium to be used as a safe ruleout' test alone. This represents the fact that hypercalcaemia and reduced renal function are late features of the disease. The researchers recommend the addition of calcium tests in the above combination in the presence of certain symptoms like back pain, rib pain, joint pain, and fracture, which have a relatively high rule-in potential (PPV $>10 \%$ ) when combined with abnormal calcium. ${ }^{9}$
Other symptoms appear to represent more advanced disease, and thus are only reported late in its course. Nausea is one of these, possibly arising from hypercalcaemia or kidney failure; similarly, breathlessness may relate to severe anaemia; and weight loss may suggest advanced multifocal disease.

It would be possible to integrate a system within the electronic health record that identifies relevant symptoms or changes in blood parameters over time to alert the clinician to the (small) possibility of myeloma. ${ }^{27}$ Patients identified in this way could be tested with PV or ESR, FBC, and calcium in some cases; if these tests were normal, myeloma could be ruled out.

\section{Funding}

This manuscript presents work carried out as part of a DPhil scholarship awarded to Constantinos Koshiaris funded by the Primary Care Research Trust, the University of Oxford, and National Institute for Health Research (NIHR) Oxford CLAHRC. This article presents independent research funded by the NIHR. The views expressed are those of the authors and not necessarily those of the NHS, the NIHR, or the Department of Health.

\section{Ethical approval}

This study was approved by the Independent Scientific Advisory Committee: protocol 09-110.

\section{Provenance}

Freely submitted; externally peer reviewed.

\section{Open access}

This article is Open Access: CC BY-NC 4.0 licence (http://creativecommons.org/ licences/by-nc/4.0/).

\section{Competing interests}

The authors have declared no competing interests.

\section{Discuss this article}

Contribute and read comments about this article: bjgp.org/letters 


\section{REFERENCES}

1. Lyratzopoulos G, Neal RD, Barbiere JM, et al. Variation in number of general practitioner consultations before hospital referral for cancer: findings from the 2010 National Cancer Patient Experience Survey in England. Lancet Oncol 2012 13(4): 353-365

2. Lyratzopoulos $\mathrm{G}$, Wardle J, Rubin G. Rethinking diagnostic delay in cancer: how difficult is the diagnosis? BMJ 2014; 349: g7400

3. Friese CR, Abel GA, Magazu LS, et al. Diagnostic delay and complications for older adults with multiple myeloma. Leuk Lymphoma 2009; 50(3): 392-400.

4. Kariyawasan CC, Hughes DA, Jayatillake MM, Mehta AB. Multiple myeloma: causes and consequences of delay in diagnosis. QJM2007; 100(10): 635-640.

5. Barrett J, Hamilton W. Pathways to the diagnosis of lung cancer in the UK: a cohort study. BMC Fam Pract 2008; 9: 31

6. Elliss-Brookes L, McPhail S, Ives A, et al. Routes to diagnosis for cancer determining the patient journey using multiple routine data sets. $\mathrm{Br} J$ Cancer 2012; 107(8): 1220-1226.

7. Howell D, Smith A, Appleton S, et al Multiple myeloma: routes to diagnosis, clinical characteristics and survival - findings from a UK population-based study. Br J Haematol 2017; 177(1): 67-71.

8. Abel GA, Mendonca SC, McPhail S, et al. Emergency diagnosis of cancer and previous general practice consultations: insights from linked patient survey data. Br J Gen Pract 2017; DOI: https://doi.org/10.3399/bjgp17X690869.

9. Shephard EA, Neal RD, Rose $P$, et al. Quantifying the risk of multiple myeloma from symptoms reported in primary care patients: a large case-control study using electronic records. Br J Gen Pract 2015; DOI: https://doi.org/10.3399/ bjgp15X683545.

10. National Institute for Health and Care Excellence. Suspected cancer: recognition and referral. NG12. London: NICE, 2015. https://uww.nice.org.uk/ guidance/ng12 (accessed 27 Jul 2018).

11. Cals JW, Chappin FH, Hopstaken RM, et al. C-reactive protein point-ofcare testing for lower respiratory tract infections: a qualitative evaluation of experiences by GPs. Fam Pract 2010; 27(2): 212-218.

12. Toriola AT, Grankvist K, Agborsangaya CB, et al. Changes in pre-diagnostic serum $\mathrm{C}$-reactive protein concentrations and ovarian cancer risk: a longitudinal study. Ann Oncol 2011; 22(8): 1916-1921.

13. Watson J, Round A, Hamilton W. Raised inflammatory markers. BMJ 2012 344: e454.

14. Iyen-Omofoman B, Tata LJ, Baldwin DR, et al. Using socio-demographic and early clinical features in general practice to identify people with lung cancer earlier. Thorax 2013; 68(5): 451-459.

15. Lim AW, Mesher D, Gentry-Maharaj A, et al. Predictive value of symptoms for ovarian cancer: comparison of symptoms reported by questionnaire, interview, and general practitioner notes. J Natl Cancer Inst 2012; 104(2): 114-124.

16. Jaeschke R, Guyatt GH, Sackett DL. Users' guides to the medical literature. III. How to use an article about a diagnostic test. B. What are the results and will they help me in caring for my patients? The Evidence-Based Medicine Working Group. JAMA 1994; 271(9): 703-707.

17. Thompson M, Van den Bruel A, Verbakel J, et al. Systematic review and validation of prediction rules for identifying children with serious infections in emergency departments and urgent-access primary care. Health Technol Assess 2012: 16(15): 1-100.

18. World Health Organization. Haemoglobin concentrations for the diagnosis of anaemia and assessment of severity Geneva: WHO 2011. http://www.who.int/ vmnis/indicators/haemoglobin/en/ laccessed 25 Jul 2018).

19. Rutjes AW, Reitsma JB, Di Nisio M, et al. Evidence of bias and variation in diagnostic accuracy studies. CMAJ 2006; 174(4): 469-476.

20. Herrett E, Gallagher AM, Bhaskaran K, et al. Data resource profile: Clinical Practice Research Datalink (CPRD). Int J Epidemiol 2015; 44(3): 827-836.

21. Edgren G, Bagnardi V, Bellocco R, et al. Pattern of declining hemoglobin concentration before cancer diagnosis. Int J Cancer 2010; 127(6): 1429-1436.

22. Mirrakhimov AE. Hypercalcemia of malignancy: an update on pathogenesis and management. N Am J Med Sci2015; 7(11): 483-493.

23. National Institute for Health and Care Excellence. Clinical Knowledge Summaries: multiple myeloma. Scenario: suspected multiple myeloma. May 2016. https://cks.nice.org.uk/multiple-myeloma\#!scenario laccessed 25 Jul 2018).

24. Alexandrakis MG, Passam FH, Ganotakis ES, et al. The clinical and prognostic significance of erythrocyte sedimentation rate (ESR), serum interleukin-6 (IL-6) and acute phase protein levels in multiple myeloma. Clin Lab Haematol 2003; 25(1): 41-46.

25. Brown RD, Snowdon L, Uhr E, et al. C-reactive protein (CRP) levels do not reflect disease status in patients with multiple myeloma. Leuk Lymphoma 1993; 9(6): 509-512.

26. Hsu DC, Wilkenfeld P, Joshua DE. Multiple myeloma. BMJ 2012; 344: d7953.

27. Kidney E, Berkman L, Macherianakis A, et al. Preliminary results of a feasibility study of the use of information technology for identification of suspected colorectal cancer in primary care: the CREDIBLE study. Br J Cancer 2015; 112(Suppl 1): S70-S76. 